\title{
The Study of Winter Wheat Biomass Estimation Model Based on
}

\section{Hyperspectral Remote Sensing}

\author{
Xiaowei Teng ${ }^{1,2,3,4,5, a}$, Yansheng Dong ${ }^{1,2,3,4, b, *}$, Lumin Meng $^{5, \mathrm{c}}$ \\ ${ }^{1}$ Beijing Research Center for Information Technology in Agriculture, Beijing 100097, China; ${ }^{2}$ National \\ Engineering Research Center for Information Technology in Agriculture, Beijing 100097, China; ${ }^{3}$ Key Laboratory \\ of Agri-informatics, Ministry of Agriculture, Beijing 100097, China; ${ }^{4}$ Beijing Engineering Research Center of \\ Agricultural Internet of Things, Beijing 100097, China; ${ }^{5}$ College of Geomatics, Xi'an University of Science and \\ Technology, Xi'an 710054, China; \\ atengxw1990@163.com, bdongys@nercita.org.cn, ${ }^{\mathrm{c}} 1193824953 @$ qq.com
}

\begin{abstract}
Biomass plays an important role in crop growth and yield formation. The study of biomass has been expanded to remote sensing sphere, which provides more ways to the obtainment of crop biomass. To carry out the study of winter wheat biomass estimation model, the field experiments were conducted at Rougu test area and Wugong test area, Shanxi Province in the cropping season 2013-2014. The biomass estimation model was based on the Time-Integrated Value of NDVI (TINDVI) and Leaf Water Content Index (LWCI), which was used to predict the winter wheat biomass. And the model was validated with the ground measured biomass. The results showed that the determination coefficient $\left(\mathrm{R}^{2}\right)$ and root mean square error (RMSE) between the measured and the estimated biomass were 0.7949 and $2.689 \mathrm{t} / \mathrm{ha}$, respectively. The estimated biomass was exactly similar to the field measured biomass, therefore this model had a good application prospect.
\end{abstract}

Key words: winter wheat; biomass; hyperspectral remote sensing; TINDVI; LWCI

\section{Introduction}

The information of crop growing and health condition is essential to the optimization of crop production $^{[1]}$. Biomass is an important indicator of crop condition monitoring ${ }^{[2]}$. The quantity of biomass affects the grain yield directly ${ }^{[3]}$. Many methods can be used to monitor crop biomass, including the estimation of remote sensing information, the prediction of crop model based on remote sensing and so on.

In recent years, a large number of scholars build numerous regression models of biomass estimation with the correlativity between remote sensing information and measured biomass, which have proved that the agronomy parameters just like Biomass and Leaf $\mathrm{N}$ could be evaluated. He Cheng used three kinds of data, the Thematic Mapper data, the 30 meters Digital Elevation Model data and field observation data, to get the functional relation which was possibly applied between vegetation biomass and remote sensing image information ${ }^{[4]}$. Liu Ming used ten spectral vegetation indices to estimate the LAI and biomass, and the consequences indicated that the correlations between ten vegetation indices and LAI, aboveground biomass were significant, thus using vegetation indexes to inverse LAI and aboveground biomass was feasible ${ }^{[5]}$. Gao Shuai designed the microwave and optical remote sensing integrated vegetation indexes with the RADARSAT-2 and HJ-1 data, and the results showed that compared with original methods, these vegetation indexes had a better evaluating performance with the structure parameters just like maize LAI, height and biomass ${ }^{[6]}$. Calera et al monitored the growth of corn and barley by applied remote sensing data, and the results showed that 
the value of TINDVI was linearly related to dry biomass ${ }^{[7]}$. With the purpose of establishing a spatial-temporal model for future TINDVI, Andreas Westergaard-Nielsen combined TINDVI and observed temperatures with a downscaled regional climate model (HIRHAM5) ${ }^{[8]}$. Hunt mentioned a leaf water content index(LWCI), which was calculated by Landsat near infrared band reflectance and shortwave infrared band reflectance, and proved that the leaf water content index had a good correlation with the relative water content ${ }^{[9]}$. Daeha Kim mentioned a biomass estimation model, which was based on the studies of Calera and Hunt ${ }^{[10]}$.

Research of remote sensing technology for biomass estimation has been undertaken by many predecessors, and they have made corresponding progress, which has made a significant contribution. However, most of the estimation models are not universal, and are only suitable for local area, which goes against the popularization of these models. Daeha Kim mentioned a biomass model based on the value of NDVI and crop information data, but the model was not been validated by the field measured biomass. The paper adopts the biomass model of Daeha Kim, and to estimate the biomass collected at Rougu test area and Wugong test area with the hyperspectral remote sensing, hoping that the model can be applied in different areas.

\section{Site description}

Field experiments were implemented in the Rougu test region and Wugong test region, Shanxi Province, China(Fig.1). The test sites are located in central of Shanxi GuanZhong Plain, which is a typical arid and semi-arid region. The average temperature of summer is $26.1^{\circ} \mathrm{C}$, and the average temperature of winter is $-1.2^{\circ} \mathrm{C}$. The average rainfall of the test sites is $635.1 \mathrm{~mm}$. The main crops of the two areas are winter wheat and summer maize. Most of the winter wheat is sowed in the middle of October, and is harvested in early June. Five times field experiments were carried out and the measured agronomy parameters(Table 1) were obtained which included wheat canopy spectra, aboveground biomass and yield. The wheat canopy spectra was measured by the America ASD FieldSpec FR 2500 field spectral radiometer. The aboveground biomass and yield were measured by wheat samples obtained from each plot.

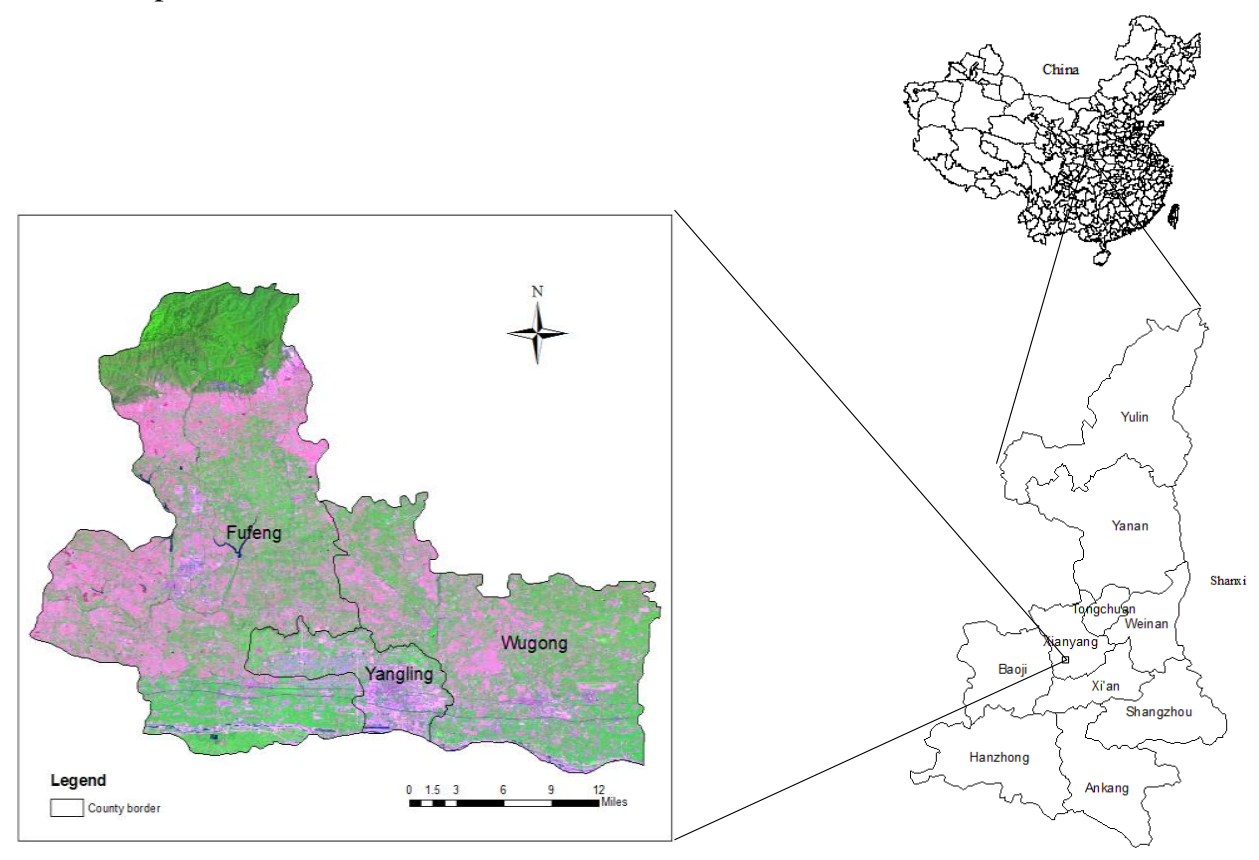

Fig.1 The study area 
Table 1 The testing time and growth period of winter wheat in the cropping season 2013-2014

\begin{tabular}{|c|c|c|c|c|c|}
\hline Testing time & Mar05-06 & Mar28-29 & Apr27 & May16-17 & Jun10 \\
\hline $\begin{array}{c}\text { Growth } \\
\text { period }\end{array}$ & Returning green stage & Jointing stage & $\begin{array}{c}\text { Heading } \\
\text { period }\end{array}$ & $\begin{array}{c}\text { Pustulation } \\
\text { period }\end{array}$ & Mature period \\
\hline
\end{tabular}

\section{Methods}

\subsection{Model Description}

Combining the previous researches ${ }^{[7,9]}$, Daeha $\mathrm{Kim}^{[10]}$ invented the biomass model which was based on TM, ETM and OLI images, and involved the growth of TINDVI and the influence of water stress. The core principle of this model is that it translates the value of TINDVI into biomass under comprehensively considering the water stress coefficient. The equation for calculating biomass production is as follows:

$$
B_{A S D}=m \times W \times T I N D V I
$$

Where $\mathrm{m}$ is conversion coefficient from the value of TINDVI to biomass. $\mathrm{W}$ is the water pressure coefficient or water pressure factor. $\mathrm{B}_{\mathrm{ASD}}$ is biomass estimated from hyperspectral remote sensing. NDVI is the Normal Differential Vegetation Index, which is computed from reflectances of red band and near infrared band ${ }^{[11]}$. TINDVI is the Time Integrated Value of NDVI. And it is calculated as:

$$
\begin{aligned}
& T I N D V I=\int_{t_{0}}^{t_{1}}\left(N D V I-N D V I_{\text {soil }}\right) d t \\
& N D V I_{A S D}=\frac{N I R-R E D}{N I R+R E D}=\frac{R_{890}-R_{670}}{R_{890}+R_{670}}
\end{aligned}
$$

Where $t_{0}$ is the start time of returning green stage, and $t_{1}$ is the time when biomass is estimated. $\mathrm{NDVI}_{\text {soil }}$ is NDVI of bare soil. RED and NIR are red band reflectances and near infrared band reflectances, respectively. $R_{890}$ and $R_{670}$ are the reflectances of 890th band and 670th band, respectively.

For dry leaves, the reflectance of shortwave infrared band is almost equal to the reflectance of near infrared band ${ }^{[12-14]}$. For green leaves, near infrared band has the maximum reflectance of the six Thematic Mapper band, whereas the shortwave infrared band reflectance is reduced because of absorption by water ${ }^{[14,15]}$. So that the difference between the shortwave infrared band reflectance and the near infrared band reflectance for the green leaves should be equivalent to the water absorptance in the green leaves ${ }^{[9]}$. Absorbance is usually calculated by $-\log (1-a)$, where a is the absorptance ${ }^{[16]}$. So that the biomass model regards the LWCI as the water pressure coefficient, and the water pressure coefficient $^{[9]}$ is defined by NIR and SWIR as:

$$
W=L W C I=\frac{-\log [1-(N I R-S W I R)]}{-\log \left[1-(N I R-S W I R)_{F T}\right]}
$$

Where SWIR is the reflectance of shortwave infrared band. This study uses the 890th and 1610th band reflectances of hyperspectral remote sensing instead of NIR and SWIR. The subscript means that the reflectances of these leaves are in the state without water stress.

The biomass conversion coefficient is associated with the region and the cultivar of winter wheat, 
which is determined by the value of TINDVI and the conservative biomass at mature. The equation of biomass conversion coefficient $\mathrm{m}$ is as follows:

$$
\dot{m}=\frac{B_{h}}{E[W \times T I N D V I]}
$$

Where $\mathrm{B}_{\mathrm{h}}$ is the conservative biomass at mature, and $\mathrm{E}[\mathrm{W} \times \mathrm{TINDVI}]$ is the average of $\mathrm{W} \times$ TINDVI in the region.

\section{2 model verification}

The $\mathrm{R}^{2}$ and RMSE were applied to evaluate the biomass estimation results. The more the $\mathrm{R}^{2}$ close to 1 , the more the consistency well. And the more the RMSE close to 0 , the more the error small. RMSE is calculated based on Eq.(6).

$$
R M S E=\sqrt{\frac{\sum_{i=1}^{n}\left(\mathrm{E}_{i}-M_{I}\right)^{2}}{n}}
$$

\section{Results and Discussions}

The estimated winter wheat biomass in the cropping season 2013-2014 was validated with the field measured biomass. In the analysis, the $\mathrm{R}^{2}$ between estimated biomass and measured biomass in the period of Mar05-06, Mar28-29, Apr27 and May16-17 were 0.2836, 0.2042, 0.3412 and 0.1976, respectively (Fig.2). The estimated biomass precision was slightly lower in single period. The maximum and minimum correlation coefficients were 0.3412 and 0.1976 , respectively. The biomass estimation precisions were in the range of acceptable precision.
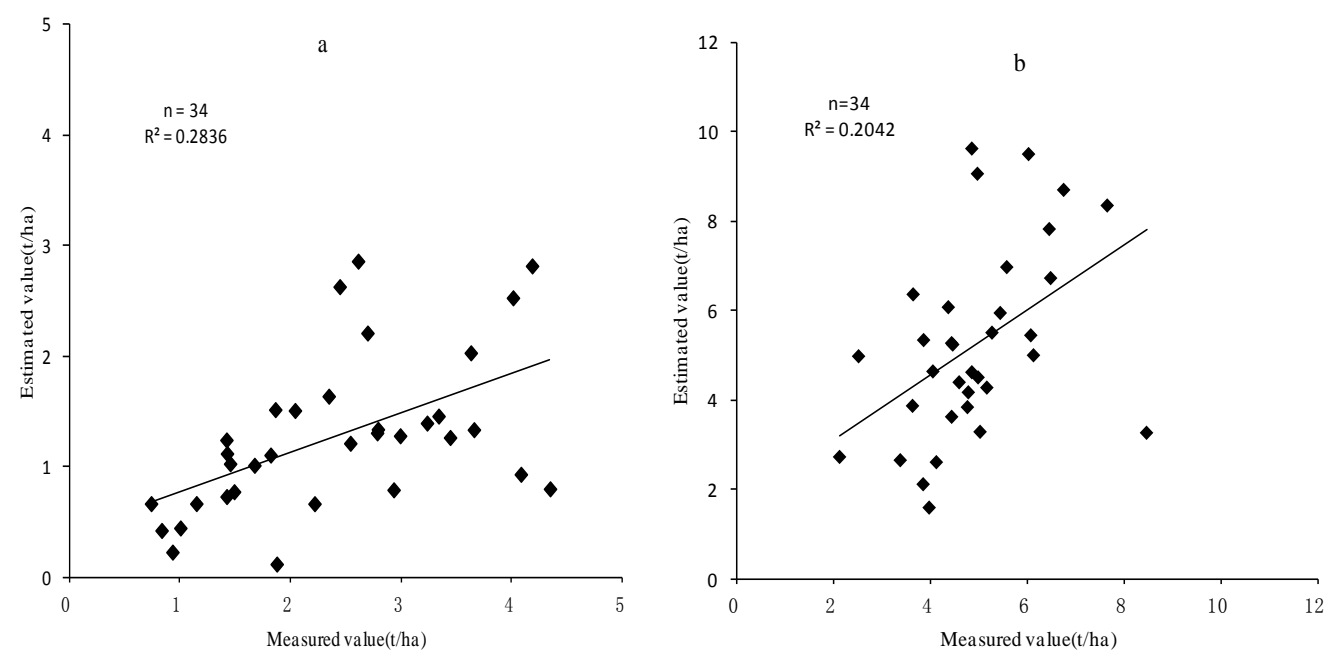

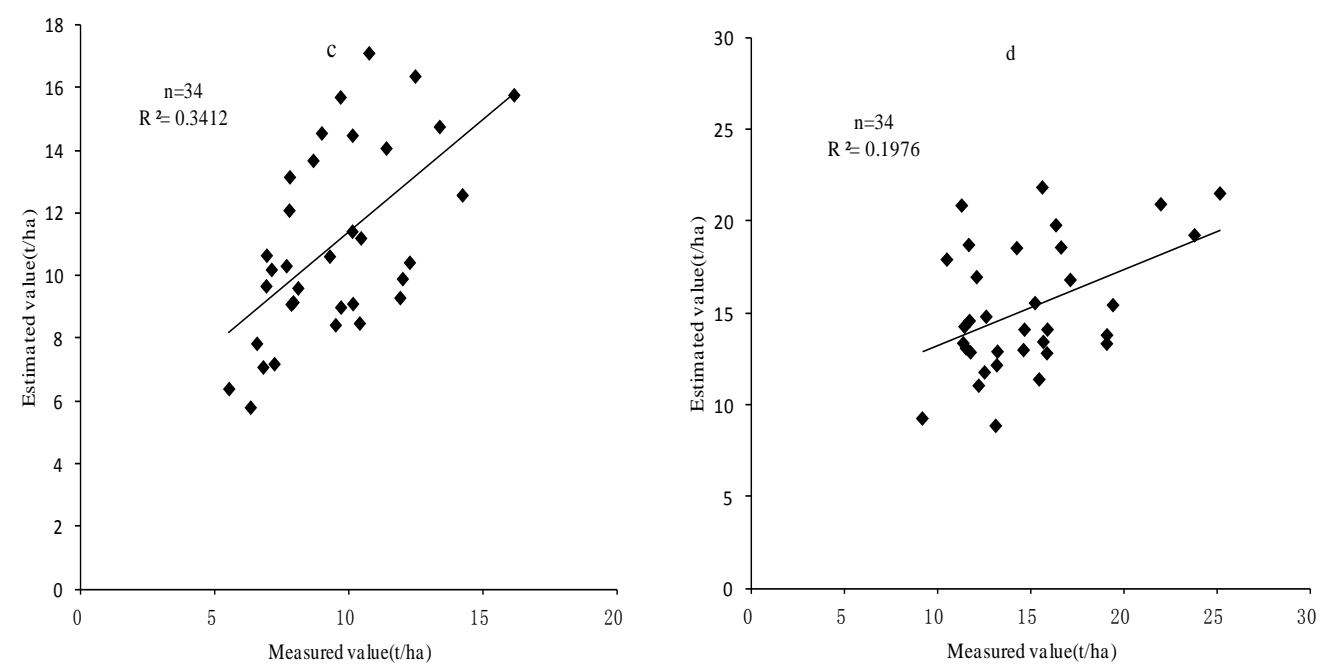

Fig.2 The relationship between estimated biomass and measured biomass in the period of Mar05-06(a),

Mar28-29(b), Apr27(c) and May16-17(d)

The $\mathrm{R}^{2}$ and RMSE between the estimated and measured biomass in the whole period of winter wheat were 0.7949 and $2.689 \mathrm{t} / \mathrm{ha}$, respectively (Fig.3). The whole period of winter wheat estimated biomass had a higher correlation with the measured biomass.

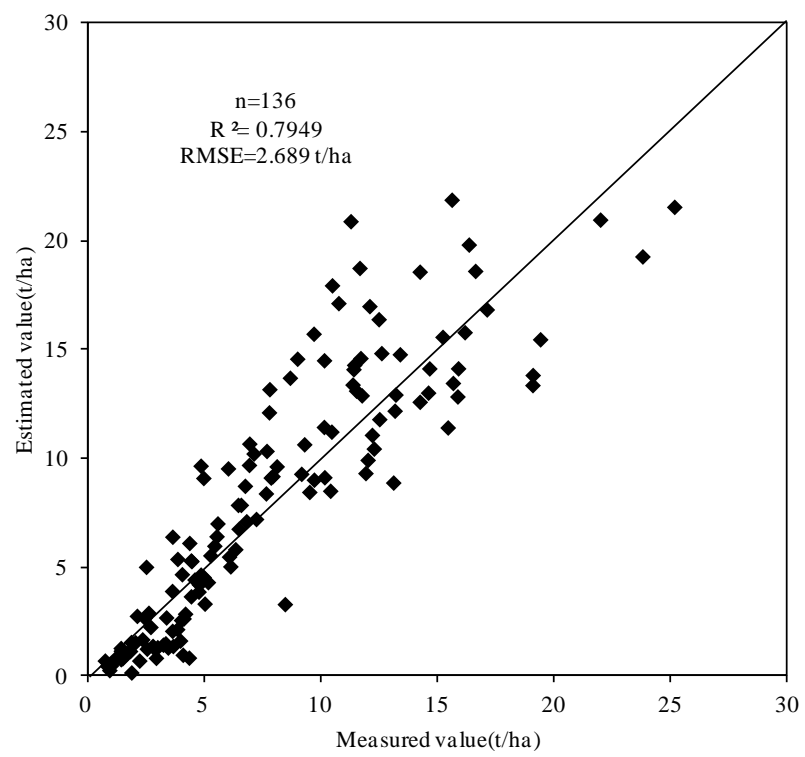

Fig.3 The relational graph between estimated biomass and measured biomass in the whole period of winter wheat

Thus, the correlations between estimated biomass and measured biomass suggested that this biomass estimation model was viable. In this study, the TINDVI and LWCI were applied to estimate the biomass of winter wheat, which has more advantages than the biomass regression models. Because it can be applied to different areas. Moreover, it combined the former studies by considering both the TINDVI growth and the effect of water stress on biomass growth ${ }^{[10]}$. But this model had little consideration on rainfall data and irrigation data. Only four biomass tests were carried out in the cropping season 2013-2014, which lead to a deviation from the NDVI real situation curve. So that the each times single predicted precisions were slightly lower. This model is a new biomass model, thus the 
further research is required to verify and perfect the model.

\section{Conclusion}

This study carried out winter wheat biomass estimation based on a new biomass model through hyperspectral remote sensing, and it was verified by the field experimental data from Rougu test area and Wugong test area. The estimated wheat biomass had a higher correlation with the field measured biomass. Certainly, more field experiments should be carried out. In order to furtherly verify and perfect the biomass model, the meteorological data and field management data should also be considered. Finally, the model should be applied to remote sensing images. This paper may be valuable in guiding further study about crop biomass estimation.

\section{Acknowledgments}

The work is supported by the National Science Foundation (NNSF) of China (41401476).

\section{References:}

1. Kross A, Mcnairn H, Lapen D, Sunohara M, Champagne C. Assessment of RapidEye vegetation indices for estimation of leaf area index and biomass in corn and soybean crops[J]. International Journal of Applied Earth Observation and Geoinformation. 2015, 34: 235-248.

2. Du X, Meng J H, and Wu B F. Overview on Monitoring Crop Biomass with Remote Sensing [J]. Spectroscopy and Spectral Analysis. 2010(11): 3098-3102.

3. Ma Q R, Li S Z, Zhao H Q, Yang G X, Wu D Y, and Dong W H. A Study on Accumulation and Increment Distribution of Biomass of Summer Maize in Zhengzhou [J]. Chinese Journal of Agrometeorology. 2007, 28(4): 430-432.

4. He C, Feng Z K, Han X, Sun M Y, Gong Y X, Gao Y, and Dong B. The Inversion Processing of Vegetation Biomass along Yongding River Based on Multispectral Information [J]. Spectroscopy and Spectral Analysis. 2012, 32(12): 3353-3357.

5. Liu M, Feng R, Ji R P, Wu J W, Wang H B, and Yu W Y. Estimation of Leaf Area Index and Aboveground Biomass of Spring Maize by MODIS-NDVI [J]. Chinese Agricultural Science Bulletin. 2015, 31(6): 80-87.

6. Gao S, Niu Z, Huang N, Hou X. Estimating the Leaf Area Index, height and biomass of maize using HJ-1 and RADARSAT-2[J]. International Journal of Applied Earth Observation and Geoinformation. 2013, 24: 1-8.

7. Calera A, González-Piqueras J, Melia J. Monitoring barley and corn growth from remote sensing data at field scale[J]. International Journal of Remote Sensing. 2004, 25(1): 97-109.

8. Westergaard-Nielsen A, Bjørnsson A B, Jepsen M R, Stendel M, Hansen B U, Elberling B. Greenlandic sheep farming controlled by vegetation response today and at the end of the 21 st Century[J]. Science of the Total Environment. 2015, 512: 672-681.

9. Hunt E R, Rock B N, Nobel P S. Measurement of leaf relative water content by infrared reflectance[J]. Remote sensing of environment. 1987, 22(3): 429-435.

10. Kim D, Kaluarachchi J. Validating FAO AquaCrop using Landsat images and regional crop information[J]. Agricultural Water Management. 2015, 149: 143-155.

11. Rouse J W, Haas R H, Schell J A, Deering D W, Harlan J C. Monitoring the vernal advancement and retrogradation (greenwave effect) of natural vegetation[M]. Texas A \& M University, Remote Sensing Center, 1974.

12. Thomas J R, Namken L N, Oerther G F, Brown R G. Estimating leaf water content by reflectance measurements[J]. Agronomy Journal. 1971, 63(6): 845-847. 
13. Rock B N, Williams D L, Vogelmann J E. In machine processing of remotely sensed data symposium[J]. Purdue University, West Lafayette, IN. 1985: 71-81.

14. Knipling E B. Physical and physiological basis for the reflectance of visible and near-infrared radiation from vegetation[J]. Remote Sensing of Environment. 1970, 1(3): 155-159.

15. Tucker C J. Remote Sensing of Leaf Water Content in the Near Infrared. US National Aeronautics and Space Administration, Goddard Space Flight Center, Greenbelt, Md[R]. NASA-TM-80291, 1979.

16. Nobel P S, Jordan P W. Transpiration stream of desert species: resistances and capacitances for a C3, a C4, and a CAM plant[J]. Journal of Experimental Botany. 1983, 34(10): 1379-1391. 